\title{
Emerging Student Learning Networks: Self- Directed Learning in an Eighth-Grade Life Science Classroom
}

\author{
Gerald P. Ardito \\ Pace University
}

\begin{abstract}
Although self-directed learning environments are common in higher education and online learning environments, they are uncommon in secondary educational settings. This mixed-method action research study, in which the author/researcher was also the teacher, reports on the design and implementation of a self-directed learning environment for eighth-grade life science students. This study investigated the impact of this type of learning environment on the behavior and achievement of students. The findings demonstrated an increase in self-regulatory behaviors, higher performance on a state-mandated final exam, and the development of complex and robust student learning networks. Implications for teaching and learning practices and suggestions for further research are discussed.
\end{abstract}

Keywords: self-directed learning; self-regulated learning; science education; K-12 education; social network analysis; student learning networks; blended learning

An abundance of research has investigated the benefits of self-directed learning on student achievement and self-efficacy (Dron \& Ostashewski, 2015; Newmann, F. M., Marks, H. M., \& Gamoran, A., 1996) Self-directed learning has been shown to enhance learning, problem-solving, and collaborative skills (Kriner, Coffman, Adkisson, Putman, \& Monaghan, 2015). Although much of this research has focused on adult learning, some of it has investigated self-directed learning in K-12 settings (Blumenfeld, Marx, Soloway, \& Krajcik, 1996; Giannakos, Krogstie, \& Aalberg, 2016). Some of this work has demonstrated a positive impact on the learning of scientific concepts and content (Peters-Burton, 2015).

Some practitioners and researchers have opposed the application of self-directed learning because they believe adolescent students are too immature and otherwise unprepared for this type of learning (Porter, McMaken, Hwang, \& Yang, 2011). This study sought to extend the research on student-centered pedagogies and strategies into the development of a self-directed learning environment for eighth-grade life science students. 


\section{Literature Review}

\section{Cooperative Freedoms}

Dron (2007) discusses education, especially formal learning, as a balance between freedoms and constraints. There exists the needs and desires of learners of all ages for autonomy in whatever setting they find themselves (Bouchard, 2011). Conversely, there are the goals, standards, and curricula associated with certain skills or content areas that students are expected to meet. Learning environments and their associated instructional designs seek in their own ways to reconcile this tension between freedom and constraint.

Paulsen's (1993) formulation of cooperative freedoms provides a useful model for understanding this dynamic system. Paulsen outlined a range of freedoms potentially available to a learner in a particular learning environment. Paulsen delineated the six dimensions of the model: 1) Place: Freedom to choose where one learns; 2) Time: Freedom to choose when one learns; 3) Pace: Freedom to choose how fast or slow one learns; 4) Medium: Freedom to choose the media used for learning; 5) Access: Freedom to learn regardless of qualifications or extrinsic obstacles; and 6) Content: Freedom to choose what one learns. This model is depicted in Figure 1.

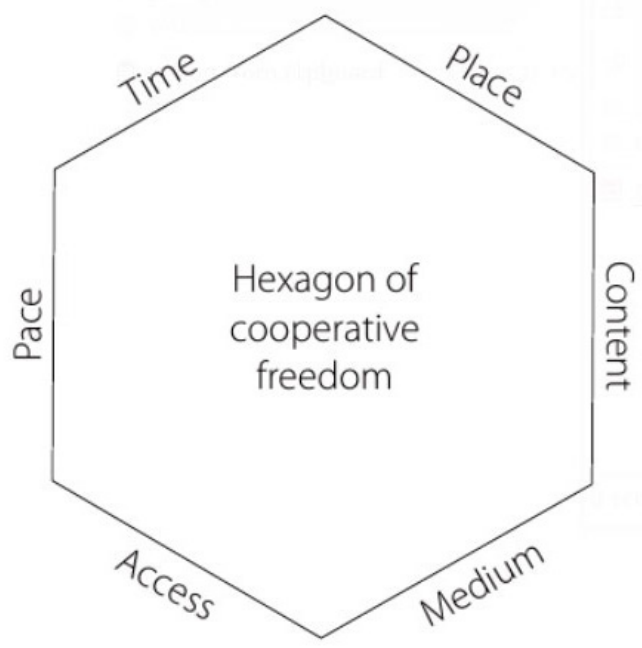

Figure 1. Paulsen's model of cooperative freedoms (from Dron and Anderson, 2014). Used with permission.

Using this model, learning environments can be categorized from the perspective of relative amounts of these cooperative freedoms. This type of analysis has been employed by other researchers. For example, Dron and Anderson (2014) indicated that in a typical instructivist setting, in which teaching follows a top-down transmission model (Dron \& Ostashewski, 2015), the instructor determines each of these dimensions, with the learner having little to no practical input. At the other end of the spectrum are relatively high degrees of cooperative freedoms in a self-directed setting. Downes (2017) has explored these types of settings through work with Connectivist Massive Open Online Courses (cMOOCs) where the learner has the greatest possible input about each of these dimensions. 
Research in K-12 schools has often focused on shorter-term instructional methods, such as peer collaboration and project-based learning, rather than on longer-term instructional methods because of the increasing demands in schools. Practitioners and researchers frequently explain this situation by citing a lack of development in adolescents in the area of self-regulation, along with increasing demands in schools from standardized and high-stakes curricula and assessment (Lazonder \& Harmsen, 2016).

\section{Student-Centered Social Constructivist Pedagogies}

A great deal of research has investigated the benefits of social constructivist pedagogies such as project-based, problem-based, and inquiry-based learning (Hay \& Barab, 2001). Project-based learning engages students in a project that is designed to deepen and apply key concepts for a particular content area or areas. Problem-based learning engages students to solve a real-world problem, typically working collaboratively with other students. Inquiry-based learning is a set of strategies that provide opportunities for learners to explore key concepts and skills for themselves. These pedagogies and strategies have been demonstrated to increase student understanding, retention, engagement, and critical thinking (Hmelo-Silver, 2004; Krajcik et al., 1998; Rhodes, 2016; Smith, Sheppard, Johnson, \& Johnson, 2005). These strategies and practices also served to increase the degree of cooperative freedoms available to learners, which resulted in the observed increases in student autonomy and ownership.

Despite observed gains in student responsibility and autonomy in K-12 settings, these social constructivist practices are typically used within traditional, instructivist learning environments. This is increasingly so under the recent pressures from high-stakes standardized testing (Ravitch, 2011). One unintended outcome of high-stakes testing has been a decrease in the use of student-centered, social constructivist pedagogies even though their use has been associated with gains in student achievement and the development of critical thinking skills (Rhodes, 2016).

\section{Self-Directed Learning Environments}

An abundance of research has investigated the benefits of self-directed learning on student achievement and self-efficacy. Self-directed learning has been shown to enhance learning, problem-solving, and collaborative skills (Kriner, Coffman, Adkisson, Putman, \& Monaghan, 2015). Although much of this research has focused on adult learning, some has investigated self-directed learning in K-12 settings (Blumenfeld, Marx, Soloway, \& Krajcik, 1996; Giannakos, Krogstie, \& Aalberg, 2016). These findings have been attributed to the increased presence of certain dimensions of Paulsen's model of cooperative freedoms allowed by such instructional design (Yüksel \& Geban, 2015). The present study sought to extend the research on other student-centered pedagogies and strategies into the development of a self-directed learning environment for eighthgrade life science students. 
The goal of this study then is to investigate the following research questions:

1. How does a self-directed learning environment affect the academic achievement of eighth-grade life science students?

2. How does a self-directed learning environment affect the collaborative behavior of eighth-grade life science students?

\section{Method}

The purpose of this study was to investigate the impact of a self-directed learning environment on the achievement and behavior of middle school life science students. As action research, a mixed methods methodology was selected for this study. Action research is appropriate and valuable where the goal of the research is to improve processes such as teaching and learning (Berg, Lune, \& Lune, 2004). Since this study necessitated an active and responsive redesign of coursework, assignments, classroom structures, and learning materials, an action research design was considered both appropriate and necessary.

In this situation, a true experimental design was not possible. Instead, a modified ex post facto design was implemented in order to investigate the outcomes from these students' experience of participating in a student-centered, self-directed learning environment. In ex post facto design, "...the researcher identifies events that have already occurred or conditions that are already present and then collects data to investigate a possible relationship between these factors and subsequent characteristics or behaviors" (Leedy \& Ormrod, 2005, p. 232).

\section{Context}

This study took place in an eighth-grade classroom in a small suburban school district about 45 minutes north of a major U.S. city. According to the 2010 Census, the population of this community is 8,000 with a median annual income of $\$ 131,000.00$ (U.S. Census Bureau, 2010). The district has three schools: one elementary school, one middle school, and one high school. In a typical year, approximately 1,600 students are enrolled in grades K-12. The participants in this study were forty-six eighth-grade students enrolled in a life science course taught by the teacher/researcher. This life science course is typically taught in a high school setting or is offered in middle school only for accelerated students. In this district, it was required for all students. At the end of the course, students completed an associated state-mandated final exam. Successful completion of the exam provides students with high school credit for the course.

During the academic year of this study, there were two sections of students who were engaged in the redesigned self-directed version of this life science course. These sections corresponded to the mathematics sections in which these students were enrolled. The middle school offered two options for mathematics courses for eighth-grade students. 
The first was a standard eighth-grade mathematics course which was composed of a pre-algebra curriculum. The second, designated as an accelerated offering, was a high school level algebra course. Placements in these mathematics sections were determined by several factors, including student GPA in seventh grade mathematics, student performance on a placement examination, teacher evaluation of student organization, preparation for an accelerated class, and student preference. Students selected for the pre-algebra mathematics curriculum generally had lower GPAs and less developed organizational skills than their algebra course peers.

The teacher/researcher was assigned to these two sections of the life science class. The first section was populated by students in the pre-algebra mathematics course and contained 16 students (9 female and 7 male). One of these students had special needs, which resulted in the development of an Individualized Educational Plan (IEP), designed to support the student's slower than average processing time. Two of these students were English Language Learners (ELLs). The second section was populated by students in the high school level algebra course and contained 30 students (13 female and 17 male), none of whom were diagnosed with special needs and all of whom were proficient in English as their primary language. The correspondence between the mathematics level and science section placement was a district decision in order to facilitate student scheduling. It did, however, have the unintended consequence of creating two relatively homogeneous groups of science students. Each section of the life science class met for six 40-minute class periods per week.

The school district and its faculty and administrative staff valued student-centered learning practices. Professional development opportunities supporting these learning practices were regularly offered to teachers throughout the year and the students involved in this research had regularly participated in collaborative and social constructivist learning activities throughout their previous academic experiences.

\section{(re)Design for Self-Directed Learning}

This study involved an innovative approach to the teaching of a high school level life science course. The curriculum for the course is governed by state approved science standards, and is comprised of a variety of topics which were organized by the teacher/ researcher into five broad units:

Homeostasis. Topics included human body systems, cell biology, biochemistry, and feedback mechanisms.

Evolution. Topics included natural selection, patterns of evolution, and some aspects of population dynamics.

Reproduction. Topics included asexual reproduction, sexual reproduction, male and female reproductive systems, and embryonic development. 
Genetics. Topics included inheritance, Mendelian genetics, molecular genetics, and bioengineering.

Ecology. Topics included food webs and chains, the flow of energy through a system, biomes, and man's impact on the environment.

To allow for the self-directed learning at the core of this study, this life science curriculum was redesigned by the teacher/researcher with four overarching principles. First, the curriculum design was accomplished according to the principles of Understanding by Design (Wiggins, McTighe, Kiernan, \& Frost, 1998), which calls for the establishment of Big Ideas and Essential Questions, which work to determine appropriate priorities and areas of focus. Second, the self-directed units were informed by a constructivist approach that allows for the individual student to interact powerfully with his/her work in a way that supports each student constructing a deep understanding of the material at hand (Honebein, 1996; Novak, 2002). Third, principles of self-regulated learning, especially in the development of a blended learning experience, as well as in the use of peer-, instructor-, and self-assessment (Gomes, 2015) were incorporated into the instructional design. This component of the redesign was also informed by several studies that investigated the role of student self-efficacy and the development of metacognitive skills in science education (Bunterm, et al., 2014; Miri, David, \& Uri, 2007; Schraw, Crippen, \& Hartley 2006; Sadeh \& Zion, 2009). Fourth, the instructional design sought to maximize the students' experience of Paulsen's cooperative freedoms and to provide them with as much choice as possible across the dimensions of place, time, pace, medium, access, and content.

\section{A Technology-Enhanced Learning Environment}

Several tools were employed to create a student-centered learning environment. Moodle, an open source learning management system (LMS), was used to map out the various learning paths utilized by the students. Moodle was selected primarily because of its ease of use as well as for its ability to support social constructivist learning (Dougiamas \& Taylor, 2003). A great deal of attention was paid to a consistent student user experience, as suggested by instructional design research (Swan, 2001). Each learning path had the same three design components or elements: Overview, which made explicit the Big Ideas and Essential Questions for the unit and provided resources and materials for the students, such as a study guide; Content Chunks, which organized the various content, readings, activities, projects, and assessments in meaningful chunks (depending on the unit, these Content Chunks may or may not have been followed sequentially); and Self-Assessment, which allowed the students to determine whether they were ready to take the culminating test for the unit. These self-assessments were sets of questions which, if answered in depth, would assure the student and teacher that the student had mastered the necessary knowledge and skills for the unit, thus providing a gateway into the cumulative exam for the unit. Figure 2 illustrates these design elements. 


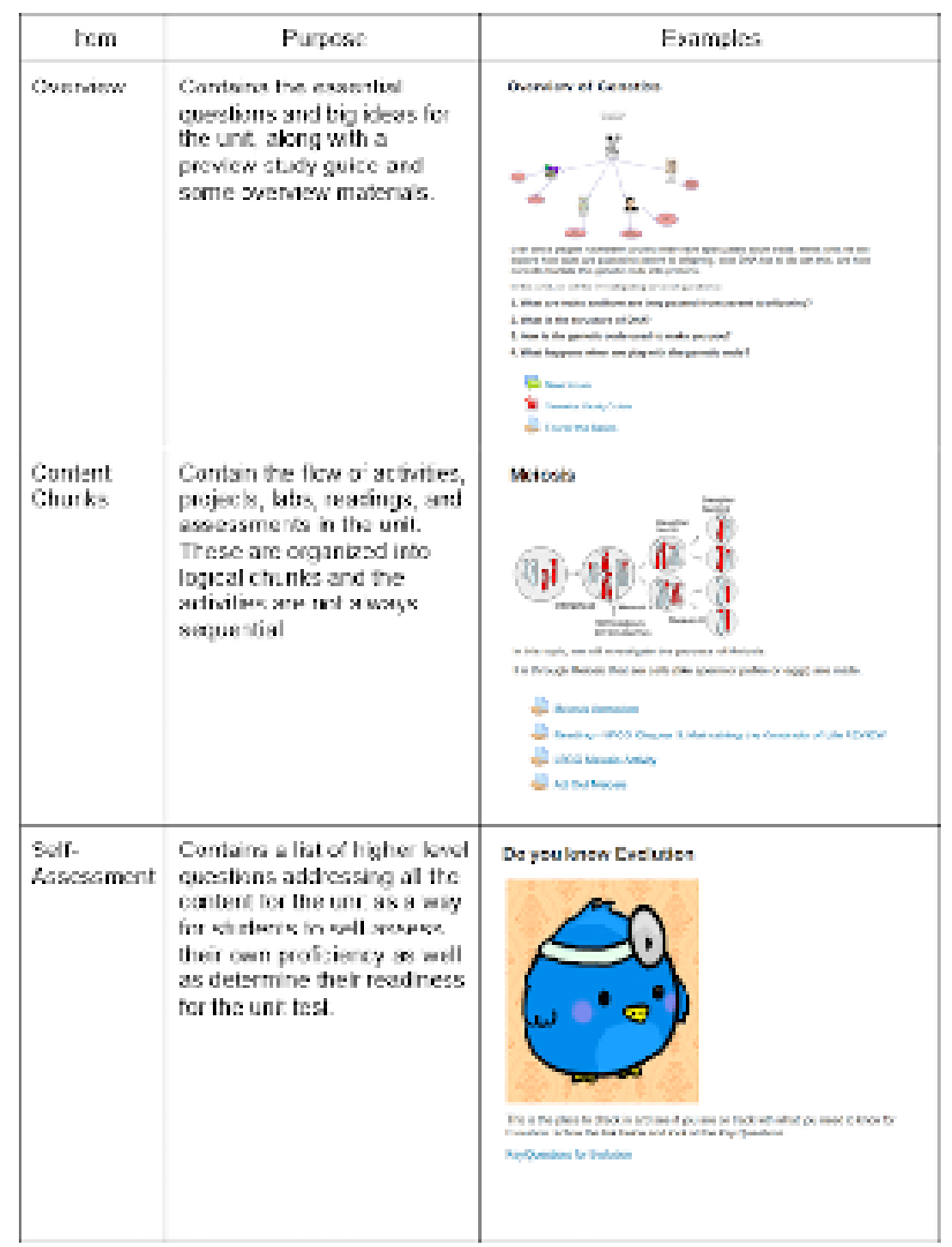

Figure 2. Design elements for online component of life science course

Moodle, like other LMS tools, has built-in discussion board functionality, which supports threaded discussions. The teacher/researcher believed that fluid communication was more consistent with the desired learning environment, and thus Edmodo, a social network designed for school use, was selected as a communication tool for this course. By using Edmodo, all members of the learning community could be in regular and simple communication with one another. The teacher/researcher used Edmodo to share resources with students and to make announcements. Students used it to communicate with one another and to ask questions of the teacher. For each unit, Edmodo groups were formed so that discussions and questions could be organized around specific content areas. 


\section{The Physical Layout}

Since effective student-centered, self-directed learning environments are characterized by student choice, the physical space was an important part of the structure for the course and was also considered in the curricular (re)design (Lim, O'Halloran \& Podlasov, 2012). The room used was a fairly large classroom (approximately 60 feet long by 18 feet wide), which allowed for a variety of seating options and configurations. Figure 3 depicts the arrangement of the classroom.

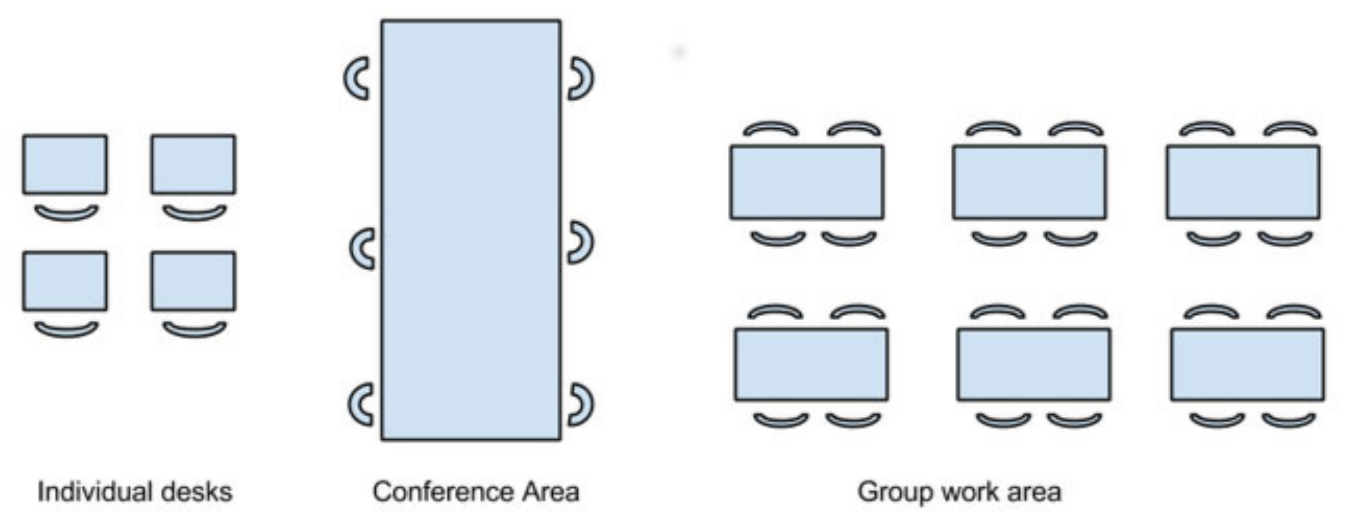

Figure 3. Physical arrangement of the classroom depicting types of seating choices.

\section{Classroom Structures and Supports}

Frequent and consistent feedback is a key component of student-centered, self-directed learning environments (Schelfhout, Dochy, \& Janssens, 2004; van Dinther, Dochy, Segers, \& Braeken, 2014). To support student learning, several processes and structures were established, including regular conferencing with students in small group and one-toone settings and written and oral feedback on weekly student progress reports. The goal of these processes and structures was to maximize the opportunities to customize appropriate support for each student.

Consistent statement of expectations. The students were informed at the beginning of the school year that they would be responsible for moving themselves through the five units that comprised the course. For the first four to six weeks of the course, the teacher/ researcher frequently reminded the students that they needed to be finished with all five units no later than June 1st, at which point the review for the state-mandated proficiency exam would take place.

Choice about collaborative work. The students were permitted to choose when and whether to work with other students. They were free to choose their own partners, unless their behavior was non-productive or disruptive. The students were also expected to come into class prepared with what they intended to accomplish for each day. 
Weekly progress reports. Students were required to submit a progress report at the end of each week. These progress reports were assigned, completed, and assessed via Edmodo. The students typically completed these progress reports on Friday and received feedback on the following Monday. In addition to written feedback, the students received oral feedback from the teacher/researcher on their progress reports during their class time.

Student conferences. Throughout the year, students were encouraged to ask for help and support whenever they needed it. This support could range from simple clarifying questions about assignments, projects, or labs to substantive questions regarding the understanding of course content and concepts. The teacher/researcher would also frequently initiate conferences with students during both formal (e.g., Genetics Mondays) and informal times. The goal of these conferences was to provide frequent, meaningful, and appropriate support to the students on a 'just in time' basis, consistent with the research on mastery learning (Guskey, 2010).

\section{Data Collection and Analysis}

This study sought to investigate the impact of a student-centered self-directed learning environment on the academic achievement and collaborative behavior of these eighthgrade life science students. This section describes the data collected and the methods utilized for analyzing them.

\section{Student Academic Achievement}

For this study, student academic achievement refers to the improvement of student scores between a pre- and post-test. Within the first two weeks of the school year, the students were given a pre-test. This pre-test was constructed of a subset of the questions typically found on the state mandated final exam. There were several design considerations employed in the construction of this pre-test:

1. Correspondence with final exam. Actual past final exam questions were used.

2. Distribution patterns. Similar patterns of distribution of content areas were used as existed on the final exam. For example, if the topic of ecology represented $40 \%$ of questions on the final exam, it also represented $40 \%$ of the questions on the pre-test.

3. Types of questions. The final exam included three types of questions: multiple choice, which required students choose the right answer from four options; short answer responses, which required a response of a word to a short phrase in length; and constructed response questions, which required more elaborate answers such as one or more sentences. The distribution of question types on the pre-test matched that of actual exams. Typically, these distributions are $60 \%$ multiple choice, $7 \%$ short answer, and 33\% constructed response. Examples of these types of questions are depicted in Figure 4. 
A Natural selection produces changes most quickly in

(1) species with short reproductive cycles

(2) individual pathogens killed by antibiotics

(3) complex multicellular organisms

(4) individuals that produce a small number of offspring

B

Saving Florida Orangess

A diseace that affects orange trees has led to the destruction of namerons conmze trees

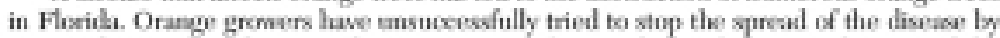
coutting down infected trees and using a variety of pestieides on the inecets that speread the disease. The growers fear that if nothing further is ckone, entire crops coskd be wiped out in the near future. In hopes of saving Fleridas arange indestry, stientists are attempeing to alker the DNA of coninge trees by inserting DNA. that codes for disease resistance, from a different plast spexies.

State the manne of the specilic technipos that is usexd to alter the DNA of arange trees. [1]

\section{C}

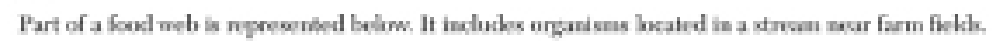

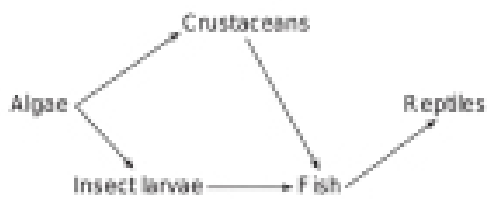

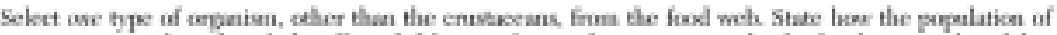
ergarians you setexted migh be affected if the populicion of enstacons in this food web were redioced doe

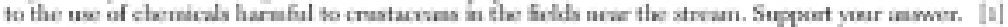

Organian:

Figure 4. Types of questions on final exam- multiple choice (A), short answer (B), and constructed response

The results of the pre-test were used to predict student performance on the final exam. The student's score on the pre-test was converted to one of the five scoring bands utilized for the state mandated final exam: 1) $95-100$, 2) $85-94$, 3) $75-84$, 4) $65-74$, and $5)<65$. A score of 65 or above on the final exam is considered passing. In order to determine gains in student achievement in this learning environment, the students' final exam score on the state mandated final exam was then compared to his/her predicted score based on the pre-test. This procedure had been used in the previous two school years and had proven a reliable indicator of student growth.

\section{Student Collaborative Behavior}

For this study, collaborative behavior refers to the ways that these students organized themselves to complete the work of the course. In order to investigate the effect of this self-directed learning experience on the students' collaborative behavior, several sets of 
data were collected. These data included 1) field notes on student-student interactions from classroom observations; 2) user data from Moodle on student progress, including records of the progress through each unit and timeliness of assignments; 3) user data from Moodle on student collaboration and working behavior, such as enrollment patterns in units (which helped determine how long students spent on units and who worked together); and 4) user data from Edmodo on student-student interactions, including discussion frequency and content.

These data were analyzed to determine trends and patterns observed in student achievement and working behavior. The research utilized Social Network Analysis (SNA) to analyze the learning networks established by students in this self-directed learning environment. SNA is a tool that allows researchers to visualize connections between people and has been used in a variety of settings (Borgatti, Mehra, Brass, \& Labianca, 2009; Granovetter, 1983). In educational research, SNA has been used to understand online learning environments. It has only rarely been used to study face-toface K-12 educational settings, but has shown strong promise (Grunspan, Wiggins, \& Goodreau, 2014). For this study, graphs of student learning networks were generated from classroom observation field notes along with Moodle and Edmodo user data. Social Network Analysis (SNA) was employed in order to perform this analysis, as was a software tool called SocNet which created the graphical representations of student interaction networks (Kalamaras, n.d.). In order to reflect the dynamic nature of these student learning networks, a type of analysis called a Fruchterman and Reingold forceddirected placement was utilized (Fruchterman \& Reingold, 1991).

\section{Findings}

\section{Student Achievement}

The key indicator of student achievement in this study was performance on a final exam. Students in this life science course were required to take a state mandated final exam, as were all their peers across the state. In order to investigate the effect of this type of learning environment on student achievement, this final exam data was examined in two ways. The first was in terms of differences in student test scores between a pre-test and the final examination. The second also considered differences in test scores between the pre-test and the final examination, but it examined these differences in the context of changes to their placement within a set of scoring bands.

Differences between pre-test and final exam scores. At the beginning of the school year, all participating students were given a pre-test which was designed as an analog to the final exam. This pre-test was shorter than the final exam, but it contained the same types of questions (e.g., multiple choice, short answer, and constructed response) in the same proportions as those found on the final exam. Figure 4 contains examples of each of these types of test questions. The pre-test also maintained the same distribution of questions by content as the final exam. These pre-test scores were used to predict the 
students' performance on the final exam. The method of calculating these predictions had been used in past years and was found to be reliable.

To investigate any gains in achievement associated with this student-centered and selfdirected learning environment, student performance was examined by comparing preand post-test exam scores. A set of paired t-tests were performed on the predicted and actual final exam scores for the entire cohort of 46 students across both course sections, as well as for the students within each of the two course sections. The differences between pre- and post-test scores for the entire cohort were found to be significant $(t=-3.90, p=.00)$, as were those for the students in the non-algebra section $(t=-3.88$, $p=.001)$ The differences between the pre- and post-test scores for the students in the algebra section were not found to be significant $(t=-2.03, p=.052)$, despite being close to the .05 level of significance.

Differences in scoring band placement. Consistent with state reporting protocols, student final exam test scores were categorized into five possible scoring bands: 1) 95100 , 2) $85-94$, 3) $75-84$, 4) $65-74$, and 5) < 65. On this final exam, a score of 65 or above is considered passing. The scores of the students in this study on both the pre-test and final exam were categorized into these same five scoring bands, and any differences were analyzed. These results are presented in Table 1

Table 1.

Student achievement through changes in final exam grading bands

\begin{tabular}{ccccccc} 
& \multicolumn{2}{c}{ Section 1 } & \multicolumn{2}{c}{ Section 2 } & \multicolumn{2}{c}{ Section 3 } \\
\cline { 2 - 7 } Amount of change & $\#$ & $\%$ & $\#$ & $\%$ & $\#$ & $\%$ \\
++ & 1 & $6 \%$ & 0 & $0 \%$ & 1 & $2 \%$ \\
+ & 10 & $63 \%$ & 6 & $20 \%$ & 16 & $35 \%$ \\
$=$ & 5 & $31 \%$ & 21 & $70 \%$ & 26 & $57 \%$ \\
- & 0 & $0 \%$ & 3 & $10 \%$ & 3 & $7 \%$ \\
-- & 0 & $0 \%$ & 0 & $0 \%$ & 0 & $0 \%$ \\
Total & 16 & $100 \%$ & 30 & $100 \%$ & 46 & $100 \%$
\end{tabular}

In order to determine the degree of change between predicted and actual final exam scores, the following coding was used: "++" represents a movement upward of two scoring bands, "+" represents a movement upward of one scoring band, "=" represents no movement in scoring bands, "-" represents a movement downward of one scoring band, and "--" represents a downward movement of two scoring bands.

The students in section 1 (the non-algebra students) demonstrated the most upward movement of scoring bands, with 11 students $(69 \%)$ having moved up by one or two bands, five students (31\%) having no change in their scoring band placement, and no students demonstrating a downward movement in scoring bands. The majority (21) of students in section 2 (the algebra section) demonstrated no movement in scoring bands 
(70\%), while six students (20\%) showed an upward movement of one scoring band, and three students (10\%) showed a downward movement of one scoring band. Overall, 17 students $(37 \%)$ across both classes showed an upward movement of at least one scoring band.

Student achievement was measured by differences in the pre-test and final exam scores. While students in section 2 saw some improvement in test scores, the students in section 1 demonstrated the largest gains both in terms of differences measured in terms of actual points as well as differences in scoring bands.

\section{Student Collaborative Behavior}

Additional sets of data were collected by the teacher/researcher. These data included field notes from classroom observations, user data from Moodle and Edmodo, informal student interviews and focus groups, and student weekly progress reports. Analyses of these data suggest that the students in this study demonstrated development in their self-regulatory skills and behaviors.

All 46 students in the study completed the entire course in time to be eligible for the state-mandated final exam. This means that each of these students completed the various readings, projects, laboratory activities, and unit tests for each of the five units comprising the course. This occurred despite none of them having been required to do so at any point prior in their academic careers. Six students (13\%) completed the course at least two weeks early. One of these six successfully completed all the units for the course four months early. This student spent the remaining four months working on an independent project of her own design to study the human nervous system.

In the design phase, it was assumed that students would proceed through each of the five units of the course in a linear fashion, progressing from one unit to the next until completing all five units. However, only 22 of the students (48\%) who completed the course did so following this expected pattern. The remaining 24 completing students $(52 \%)$ ended up choosing to work on more than one unit at the same time. This phenomenon was not even considered as a possibility in the design phase of the course. After the first unit, however, some students requested this option. Some did so because they saw connections between units (for example, between genetics, evolution, and reproduction) or because they began to see their learning time as more fluid than it would be in a more traditional learning environment where the instructor alone sets the pace and sequence of course content. For instance, some rationalized their choice as wanting to work on one unit during school and another at home. This is a very rare occurrence in a more typical learning environment, and yet it ended up forming the dominant pattern of completion for these students.

This completion pattern was evidenced in both sections of the course, but with some notable differences. The distribution of students choosing this non-linear completion pattern was fairly evenly distributed across the two sections, despite the difference in numbers of students in each section. In the algebra section, 13 students $(43 \%)$ ended 
up working this way. In the non-algebra section, 12 students $(60 \%)$ ended up doing so. However, there were differences between the sections at the onset of this behavior. Students in the algebra section, for the most part, adopted this completion pattern within the first 10 weeks of the course, while their peers in the non-algebra section did so only within the last 12 weeks of the course. It was as though the same contagion had spread through both sections but in a staggered sequence.

Other self-regulatory behaviors emerged throughout this study. At about six weeks prior to the end of the school year, some individual students began asking the teacher/researcher about the anticipated length of certain projects and activities. When questioned, these students indicated that they were creating calendars to manage their remaining work. This behavior was not quantified, but certain patterns emerged. This calendar making took place only in the algebra section of the course and began with a small number of students. It then spread to many others in this section while never crossing course sections to the non-algebra students.

\section{Student Learning Networks}

Classroom observation notes and user data from Moodle and Edmodo were analyzed in order to document the ways in which the students in each section collaborated over the school year. From these data, the frequency of interactions between students, the number of connections between students, and the weight of these connections were identified. Student connections and interactions were visualized as the graph depicted in Figure 5.

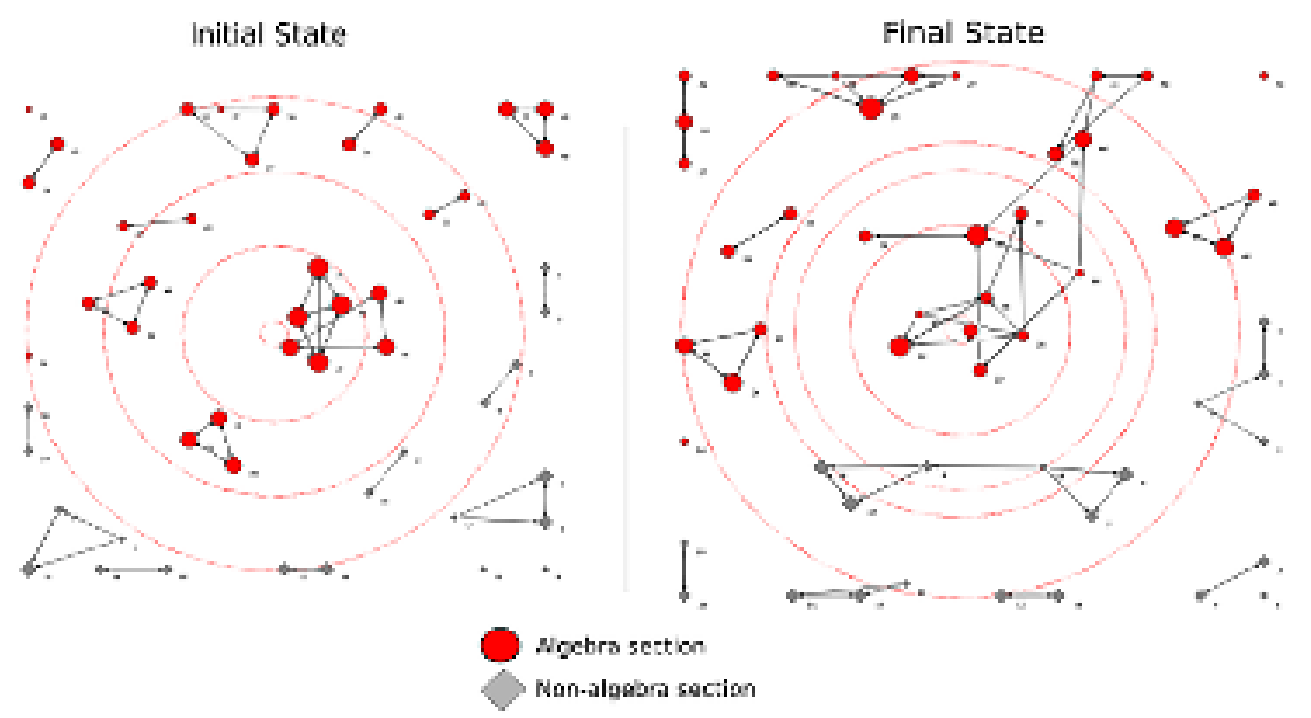

Figure 5. Social network graphs of the participants at two points of time.

This figure depicts a graph of student interactions at two points in the school year. The first, on the left, represents students' interactions within the first two weeks of the school year. The second, on the right, represents students' interactions as of the last two weeks 
of the school year. Both class sections are depicted in this graph. The non-algebra section is represented by gray triangles. The algebra section is represented by red circles. Each individual symbol (circle or triangle) depicts a student, and lines between students indicate connections. The size of the circles or triangles indicate the size of the role that student played in those relationships. The bigger the symbol, the larger the role played by the student in that relationship.

As the left side of the figure demonstrates, students began forming small groups, organizing themselves into mostly dyads and triads. Some students chose to work on their own and are represented as single nodes. This initial pattern was consistent for both sections of the course. However, by the time the students had spent most of the school year working in this self-directed way, these student learning networks had evolved, revealing greater complexity.

In the non-algebra section, this complexity is primarily centered on two female students whose connection to one another joined a pair of triads. In the algebra section, the patterns of networking were much more complex and demonstrated in two groupings. The first is the elaborate form in the center of the graph on the right side of the figure, where more than half of the students are connected in various ways. These students developed a fluid set of working relationships over the course of the year and varied in their day to day work between smaller and larger groupings. Typically, when engaged in laboratory experiences or larger projects, they formed a larger collective. For more routine work, they tended to work with one or two students at a time. The second pattern is the grouping of five students located in the upper left quadrant of the graph on the right. In this one, four male students are connected to one female student, as indicated by the size of her node. This girl was the student who completed the course four months early. She did not work directly with any of them, but rather took on a mentoring role which was quite beneficial to the boys.

\section{Discussion}

This mixed methods action research study sought to investigate the impact of a selfdirected learning environment on the academic achievement and collaborative learning behavior of eighth-grade life science students.

Perhaps the most striking finding of this study is that students were successful within this self-directed, student-centered learning environment despite having essentially no prior experience with this type of milieu. All of them successfully completed all five units of the course and all projects, laboratory activities, and assessments contained therein. It is important to note that no self-efficacy or self-regulation criteria were explicitly used in the placement of these students into these two sections.

Moreover, the findings of this study suggest a strong relationship between the implementation of a self-directed learning environment and the development of selfregulatory behaviors on the part of the students. These students - again, without 
extensive prior experience - were able to organize themselves into effective working units, to then manage themselves to complete the five units of the course, and to do so over the course of an entire school year. Certainly, the teacher/researcher provided support to them, both in terms of content and organization, but they were required and expected to manage their work and learning for themselves.

The findings of this study also indicate the potential benefits of self-directed learning environments on student achievement. Student learning was assessed throughout the course, but for the purposes of this study, the students' performance on a state mandated final exam was used as the primary indicator of student achievement. The entire cohort of students saw increases between their predicted performance on the final exam and their actual performance on the final examination, with an average of a 3-point gain per student. The lower achieving students, those in the non-algebra section, showed about twice the average point gain per student (6.2 points) as well as a statistically significant improvement between the pre- and post-test scores, as indicated by a paired t-test. These performance gains were also demonstrated by an analysis of changes to scoring band levels between the pre- and post-test conditions, as illustrated in Table 1.

Despite the fact that it is not possible to establish a causal relationship between student performance on the state-mandated final exam and a self-directed learning environment, the findings of the study are notable. These finding are in line with recent research on active learning and learning paths (Cicuto \& Torres, 2016; De Smet, De Wever, Schellens, \& Valcke, 2016).

Perhaps the most striking finding of this study is the emergence of student learning networks. The students evolved from working in simple dyads and triads at the beginning of the school year to forming more complex and robust student learning networks by the end of the year. As a result of these intricate webs of connections, self-regulatory behaviors that emerged, such as working on more than one unit at a time or implementing a planning calendar, were able to spread through the classes, and spread more effectively and quickly through the section in which students had formed the most complex and robust connections.

The findings also suggest a relationship between the gains in academic achievement and the development of student learning networks. In general terms, the largest gains in academic achievement as measured by the final exam scores took place with students who had the larger and more robust learning networks. These gains, as suggested above, were larger in the non-algebra section of the course, suggesting that actions and settings that support the development of these student learning networks might be more beneficial to lower achieving students and students with special needs. These data might also suggest that higher achieving students are already more capable and have more opportunities to create these types of learning networks; therefore, the overall effect was smaller. 
These findings are consistent with those of related research on online and distance learning settings (Centola, 2015; Hartnett, St. George, \& Dron, 2011; Shea \& Bidjerano, 2010). At present, there is a paucity of research on these types of self-directed learning environments in K-12 blended or face-to-face settings to further substantiate these findings. Further research should be done on the development and implementation of similar types of self-directed learning in K-12 environments and the identification of which teacher and student factors are most critical to success. Here, the extensive research on Communities of Inquiry (Garrison, Anderson, \& Archer, 1999) should be useful and instructive. Two such studies are currently under way by the author.

\section{Conclusion}

The development of self-regulatory skills in pre-adolescents and adolescents is a goal in K-12 education. This study suggests that the development of these skills is closely tied to the types of learning settings in which the primary and secondary students are placed. Although traditional instructivist settings provide a great deal of structure and control, they are not as effective as more constructivist, student-centered settings in the development of self-regulatory and related skills such as critical thinking and problemsolving, which are often cited as core learning objectives (Cicuto \& Torres, 2016; De Smet, De Wever, Schellens, \& Valcke, 2016).

This study demonstrated the positive effects of this type of self-directed, studentcentered learning environment for eighth-grade life science students on both their academic achievement and their development as independent learners and that this type of setting is indeed feasible in a K-12 setting. Further, the biggest gains in both of these areas were seen in lower performing students and students with special needs. Certainly, additional work is needed to further investigate and validate these findings, but the present study offers a solid start. It is hoped that the exploration of self-directed learning environments will help shape future research and practice. 


\section{References}

Anderson, T., \& Dron, J. (2010). Three generations of distance education pedagogy. The International Review of Research in Open and Distributed Learning, 12(3), 80-97. https://doi.org/10.19173/irrodl.v12i3.890

Berg, B. L., Lune, H., \& Lune, H. (2004). Qualitative research methods for the social sciences (5th ed., Vol. 5). Boston, MA: Pearson.

Blumenfeld, P. C., Marx, R. W., Soloway, E., \& Krajcik, J. (1996). Learning with peers: From small group cooperation to collaborative communities. Educational Researcher, 25(8), 37-40. https://doi.org/10.3102/0013189X025008037

Borgatti, S. P., Mehra, A., Brass, D. J., \& Labianca, G. (2009). Network analysis in the social sciences. Science, 323(5916), 892-895. https://doi.org/10.1126/ science. 1165821

Bouchard, P. (2011). Network promises and their implications. RUSC. Universities and Knowledge Society Journal, 8(1), 288-302. https://doi.org/10.7238/rusc.v8i1.960

Bunterm, T., Lee, K., Ng Lan Kong, J., Srikoon, S., Vangpoomyai, P., Rattanavongsa, J., \& Rachahoon, G. (2014). Do different levels of inquiry lead to different learning outcomes? A comparison between guided and structured inquiry. International Journal of Science Education, 36(12), 1937-1959. https://doi.org/10.1080/09500 $\underline{693.2014 .886347}$

Centola, D. (2015). The social origins of networks and diffusion. American Journal of Sociology, 120(5), 1295-1338. https://doi.org/10.1086/681275.

Cicuto, C. A. T., \& Torres, B. B. (2016). Implementing an active learning environment to influence students' motivation in biochemistry. Journal of Chemical Education, 93(6), 1020-1026. https://doi.org/10.1021/acs.jchemed.5b00965

De Smet, C., De Wever, B., Schellens, T., \& Valcke, M. (2016). Differential impact of learning path based versus conventional instruction in science education. Computers \& Education, 99, 53-67. https://doi.org/10.1016/j. compedu.2016.04.001

Dougiamas, M., \& Taylor, P. (2003). Moodle: Using learning communities to create an open source course management system. In D. Lassner \& C. McNaught (Eds.), ED-MEDIA 2003--World Conference on Educational Multimedia, Hypermedia \& Telecommunications. Honolulu, Hawaii.

Downes, S. (2017). New models of open and distributed learning. In M. Jemni, Kinshuk, \& M. K. Khribi (Eds.), Open Education: from OERs to MOOCs (pp. 1-22). Berlin, Heidelberg: Springer Berlin Heidelberg. https://doi.org/10.1007/978-3-662$\underline{52925-61}$ 
Dron, J. (2007). Control and constraint in e-learning: Choosing when to choose. Hershey, PA: IGI Global.

Dron, J., \& Ostashewski, N. (2015). Seeking connectivist freedom and instructivist safety in a MOOC. Educación XX1, 18(2), 51-76. https://doi.org/10.5944/ educxx1.14595

Fruchterman, T. M. J., \& Reingold, E. M. (1991). Graph drawing by force-directed placement. Software: Practice and Experience, 21(11), 1129-1164. https://doi. org/10.1002/spe.4380211102

Garrison, D. R., Anderson, T., \& Archer, W. (1999). Critical inquiry in a text-based environment: Computer conferencing in higher education. The Internet and Higher Education, 2(2), 87-105. https://doi.org/10.1016/S1096-7516(00)00016-6

Giannakos, M., Krogstie, J., \& Aalberg, T. (2016). Toward a learning ecosystem to support flipped classroom: A conceptual framework and early results. In Y. Li, M. Chang, M. Kravcik, E. Popescu, R. Huang, Kinshuk, \& N.-S. Chen (Eds.), Stateof-the-Art and Future Directions of Smart Learning. Lecture Notes in Educational Technology (pp. 105-114). Singapore, Springer. https://doi.org/10.1007/978-981287-868-7 12

Gomes, G. (2014). Blended learning, student self-efficacy and faculty an interpretative phenomenological analysis (Unpublished doctoral dissertation). Northeastern University, Boston, MA.

Granovetter, M. (1983). The strength of weak ties: A network theory revisited. Sociological Theory, 1(1983), 201-233. https://doi.org/10.2307/202051

Grunspan, D. Z., Wiggins, B. L., \& Goodreau, S. M. (2014). Understanding classrooms through social network analysis: A primer for social network analysis in education research. CBE Life Sciences Education, 13(2), 167-178. https://doi. org/10.1187/cbe.13-08-0162

Guskey, T. R. (2010). Lessons of mastery learning. Educational Leadership, 68(2), 5257.

Hartnett, M., St. George, A., \& Dron, J. (2011). Examining motivation in online distance learning environments: Complex, multifaceted, and situation-dependent. International Review of Research in Open and Distance Learning, 12(6), 20-38. https://doi.org/10.19173/irrodl.v12i6.1030 
Hay, K. E., \& Barab, S. A. (2001). Constructivism in practice: A comparison and contrast of apprenticeship and constructionist learning environments. Journal of the Learning Sciences, 10(3), 281-322. https://doi.org/10.1207/ S15327809JLS1003 3

Hmelo-Silver, C. E. (2004). Problem-based learning: What and how do students learn? Educational Psychology Review, 16(3), 235-266. https://doi.org/10.1023/ B:EDPR.0000034022.16470.f3

Honebein, P. C. (1996). Seven goals for the design of constructivist learning environments. In B. G. Wilson (Ed.), Constructivist learning environments: Case studies in instructional design (pp. 11-24). Engelwood Cliffs, NJ: Educational Technology Publications, Inc.

Kalamaras, D. (n.d.). Social network visualizer (SocNetV). Retrieved from http://socnetv. sourceforge.net

Krajcik, J., Blumenfeld, P. C., Marx, R. W., Bass, K. M., Fredricks, J., \& Soloway, E. (1998). Inquiry in project-based science classrooms: Initial attempts by middle school students. Journal of the Learning Sciences, 7(3-4), 313-350. https://doi. org/10.1080/10508406.1998.9672057

Kriner, B. A., Coffman, K. A., Adkisson, A. C., Putman, P. G., \& Monaghan, C. H. (2015). From students to scholars: The transformative power of communities of practice. Adult Learning, 26(2), 73-80. https://doi. org/10.1177/1045159515573021

Lazonder, A. W., \& Harmsen, R. (2016). Meta-analysis of inquiry-based learning: Effects of guidance. Review of Educational Research, 86(3), 681-718. https://doi. org/10.3102/0034654315627366

Leedy, P. D., \& Ormrod, J. E. (2005). Practical research (8 ${ }^{\text {th }}$ ed.). New York, NY: Pearson.

Lim, F. V, O'Halloran, K. L., \& Podlasov, A. (2012). Spatial pedagogy: Mapping meanings in the use of classroom space. Cambridge Journal of Education, 42(2), 235-251. https://doi.org/10.1080/0305764X.2012.676629

Miri, B., David, B. C., \& Uri, Z. (2007). Purposely teaching for the promotion of higherorder thinking skills: A case of critical thinking. Research in science education, 37(4), 353-369. https://doi.org/10.1007/s11165-006-9029-2

Newmann, F. M., Marks, H. M., \& Gamoran, A. (1996). Authentic pedagogy and student performance. American Journal of Education, 104(4), 280-312. https://doi. org/10.1086/444136 
Novak, J. D. (2002). Meaningful learning: The essential factor for conceptual change in limited or inappropriate propositional hierarchies leading to empowerment of learners. Science Education, 86(4), 548-571. https://doi.org/10.1002/sce.10032

Peters-Burton, E. (2015). Outcomes of a self-regulated learning curriculum model. Science \& Education, 24(7-8), 1-31. https://doi.org/10.1007/s11191-015-9769-3

Ravitch, D. (2011). The death and life of the great American school system: How testing and choice are undermining education. New York, NY: Basic Books.

Rhodes, A. (2016). Effects of constructivist approach in science (Unpublished master's thesis). California State University, Northridge, CA.

Sadeh, I., \& Zion, M. (2009). The development of dynamic inquiry performances within an open inquiry setting: A comparison to guided inquiry setting. Journal of Research in Science Teaching, 46(10), 1137-1160. https://doi.org/10.1002/ tea.20310

Schelfhout, W., Dochy, F., \& Janssens, S. (2004). The use of self, peer and teacher assessment as a feedback system in a learning environment aimed at fostering skills of cooperation in an entrepreneurial context. Assessment \& Evaluation in Higher Education, 29(2), 177-201. https://doi. org/10.1080/0260293042000188465

Schraw, G., Crippen, K. J., \& Hartley, K. (2006). Promoting self-regulation in science education: Metacognition as part of a broader perspective on learning. Research in Science Education, 36(1-2), 111-139. https://doi.org/10.1007/s11165-005$\underline{3917-8}$

Shea, P., \& Bidjerano, T. (2010). Learning presence: Towards a theory of self-efficacy, self-regulation, and the development of a communities of inquiry in online and blended learning environments. Computers \& Education, 55(4), 1721-1731. https://doi.org/10.1016/j.compedu.2010.07.017

Siemens, G. (2005). Connectivism: A learning theory for the digital age. International Journal of Instructional Technology and Distance Learning, 2(1), 3-10.

Smith, K. A., Sheppard, S. D., Johnson, D. W., \& Johnson, R. T. (2005). Pedagogies of engagement: Classroom-based practices. Journal of Engineering Education, 94(1), 87-101. https://doi.org/10.1002/j.2168-9830.2005.tb00831.x

Swan, K. (2001). Virtual interaction: Design factors affecting student satisfaction and perceived learning in asynchronous online courses. Distance Education, 22(2), 306-331. https://doi.org/10.1080/0158791010220208 
van Dinther, M., Dochy, F., Segers, M., \& Braeken, J. (2014). Student perceptions of assessment and student self-efficacy in competence-based education. Educational Studies, 40(3), 1-22. https://doi.org/10.1080/03055698.2014.898577

Wiggins, G. P., McTighe, J., Kiernan, L. J., \& Frost, F. (1998). Understanding by design. Alexandria, VA: Association for Supervision and Curriculum Development.

Yüksel, M., \& Geban, Ö. (2015). Examination of science and math course achievements of vocational high school students in the scope of self-efficacy and anxiety. Journal of Education and Training Studies, 4(1), 88-100. https://doi. org/10.11114/jets.v4i1.1090 